\title{
A CONVENIENT APPARATUS FOR SUGAR ESTIMATION.
}

By Alfred W. Stokes, F.C.S.

IN the discussion that ensued on the reading of Dr. Vieth's paper, Mr. A. W. Stokes, F.C.S., stated that the method he had used to verify the readings of Dr. Vieth's polariscope, was that described by Mr. Bodmer and himself in The ANalyst (vol. X. p. 62). Dr. Pavy's ammoniacal cupric solution was used. A greatly improved apparatus was, however, employed; this he exhibited to the Society. We give herewith a drawing of 
it, * noting that it may be useful for other colour reactions. It consists of a buretto one, lateral, half of which is of opal glass to show more sharply the divisions, and to mark accurately the centre of the meniscus. From this is pendent, by a short piece of india-rubber tubing, a flask of about 150 c.c. capacity. The cork used is of india rubber, with two perforations; into one of these fits a short glass tube, connected with the burette by the piece of tubing mentioned above, and dipping a short way into the flask, where it is drawn out to a moderately fine point. The other perforation is fitted with a tube leading off to two Woulffe's bottles, one of which is about one-third filled with water.

The tube between the flask and burette is best compressed by the specially-devised screw-tap figured. The ordinary spring-clip brings the fingers too close to the flame to be pleasant; nor does it allow so regular a succession of drops to fall. Behind the flask, to form a white background, is arranged the half of one of the ordinary white, opal gas-globes. By this white light is concentrated on the flask, and an admirable background formed. The method of using is described in the paper referred to above. The results obtained agree very closely with those of the polariscope.

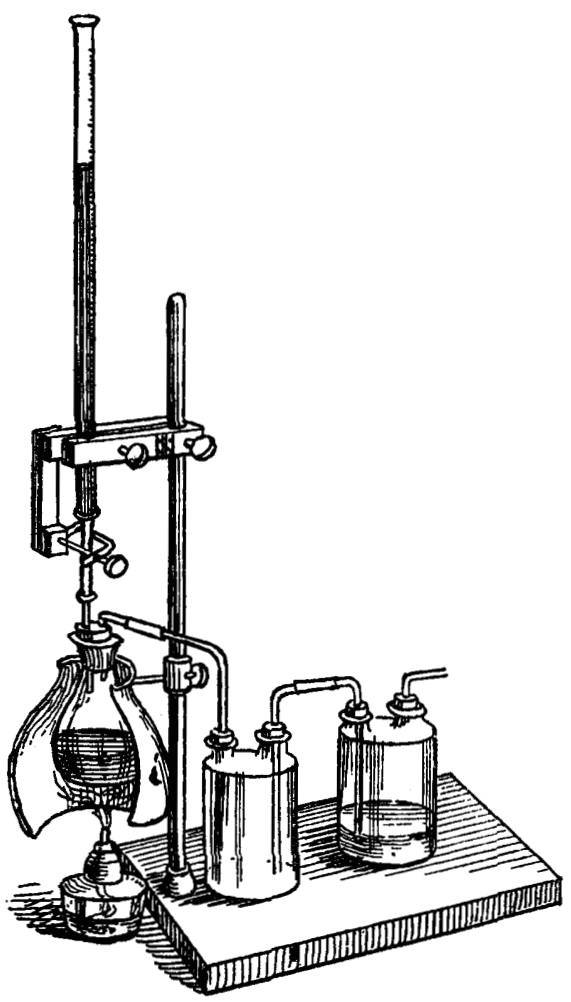

